\title{
Crenças de adolescentes portugueses sobre o uso do preservativo
}

\section{Portuguese adolescent's beliefs in relation to the use of the condom}

\section{Creencias de adolescentes portugueses con respecto al uso del condón}

\author{
Simone Helena dos Santos OliveiraI, Margarida da Silva Neves Abreu ${ }^{\mathrm{II}}$,
} Maria Grasiela Texeira Barroso ${ }^{\mathrm{III}}$, Neiva Francenely Cunha Vieira ${ }^{\mathrm{IV}}$

\footnotetext{
I Enfermeira. Doutoranda. Bolsista CAPES. Professora da Universidade Federal da Paraíba. João Pessoa, PB. E-mail: simonehso@yahoo.com.br.

II Enfermeira. Doutora. Professora da Escola Superior de Enfermagem do Porto. Porto, Portugal. E-mail: mabreu@esenf.pt.

III Enfermeira. Doutora. Professora Emérita da Universidade Federal do Ceará (UFC). Fortaleza, CE. E-mail: grasiela@ufc.br.

IV Enfermeira. PhD pela Universidade de Bristhon, Inglaterra. Diretora da Faculdade de Farmácia, Odontologia e Enfermagem da UFC. Fortaleza, CE. E-mail: neivafrancenely@hotmail.com.
}

\section{RESUMO}

Esta pesquisa revela os resultados obtidos durante Doutorado Sandwich, que incluiu trabalho de campo realizado em Portugal e que teve a CAPES como agência financiadora. Seus objetivos foram: identificar as crenças comportamentais e normativas de adolescentes em relação ao uso do preservativo durante as relações sexuais e apresentar sugestões práticas que possam contribuir à definição de estratégias sólidas relacionadas ao Programa de Educação da Sexualidade na Escola. Estudo quantitativo, com base na Theory of Reasoned Action - TRA, realizado em escolas públicas do Porto, de janeiro a março de 2008. A amostra constou de 252 adolescentes, de 13 a 19 anos, que responderam a um questionário estruturado. A idade média dos participantes foi de 14,7 anos. As vantagens para o uso do preservativo foram: prevenção de DSTs, da gravidez e da SIDA. As desvantagens foram: risco de romper, diminuição do prazer e incômodo. Entre os referentes positivos se destacaram amigos, pais e família. Os resultados obtidos revelaram crenças positivas e negativas, podendo àquelas serem reforçadas e estas minimizadas ou transformadas em positivas, durante as estratégias do programa que vem sendo desenvolvido nas escolas, servindo de contribuição para que os jovens exerçam uma vida sexual saudável.

Descritores: Saúde do Adolescente; Preservativos; Síndrome de Imunodeficiência Adquirida.

\section{ABSTRACT}

This research shows the results obtained during PhD Sandwich that includes field work carried in Portugal and had the funding agency CAPES. The goals were: to identify adolescents' behavior and normative beliefs toward condom use during the sexual relationships and to develop practical suggestions that can contribute to the definition of solid strategies related to the Sexuality Education Program in the School. Quantitative study, based on the Theory of Reasoned Action - TRA, accomplished at public schools of Porto, from January to March of 2008. The sample consisted in 252 teenagers from 13 to 19 years old that answered a structured questionnaire. The medium age was of 14,7 years old. The advantages for the use of the condom were: prevention of DSTs, of the pregnancy and of SIDA. The disadvantages were: risk of breaking, decrease of the pleasure and discomfort. Among positives persons were highlighted friends, parents and family. The results showed beliefs positive and negative, the positive can be strengthened and the negative minimized or turned into positive during the strategies of the program, that it has been developed at the schools, serving as a contribution to young people carry on a healthy sexual life.

Descriptors: Adolescent Health; Condoms; Acquired Immunodeficiency Syndrome

\section{RESUMEN}

Esta investigación muestra los resultados obtenidos durante el Doctorado Sandwich que incluye el trabajo del campo llevado a cabo en Portugal y tenía como organismo de financiación la CAPES. Las metas fueran: identificar las creencias de comportamiento y normativas de adolescentes con respecto al uso de condón durante las relaciones sexuales y proponer sugerencias prácticas que pueden contribuir a la definición de estrategias sólidas relacionadas al Programa de Educación de Sexualidad en la Escuela. Investigación cuantitativa, basado en la Theory of Reasoned Action-TRA, realizado en escuelas públicas de Porto, de enero a marzo de 2008. La muestra consistió en 252 adolescentes de 13 a 19 años que contestaron un cuestionario estructurado. La edad media de los participantes fue de 14,7 años. Las ventajas para el uso del condón fueran: la prevención de DSTs, del embarazo y de SIDA. Las desventajas fueran: el riesgo de romper, disminución del placer y incómodo. Entre los referentes positivos se destacaran amigos, padres y familia. Fue pequeño el número de referentes negativos mencionados. Los resultados mostraron las creencias positivas y negativas, el positivo puede fortalecerse y el negativo minimizarse o se convirtir en el positivo durante las estrategias del programa que se ha desarrollado en las escuelas, sirviendo de contribución a que los jóvenes desempeñen una vida sexual saludable.

Descriptores: Salud del Adolescente; Condones; Síndrome de Inmunodeficiencia Adquirida. 


\section{INTRODUÇÃO}

Diante das graves repercussões da AIDS para a vida dos adolescentes e para a sociedade e, de acreditar que a realidade de Portugal, no concernente às políticas públicas para melhoria da qualidade de vida e de saúde da população, em muito difere do Brasil, propôs-se a aproximação in loco das ações preventivas a AIDS direcionadas aos adolescentes e, paralelamente, a realização de um estudo para investigar as crenças destes quanto ao uso do preservativo durante as relações sexuais. Esta proposta se materializou através de um estágio de doutorado realizado na Cidade do Porto - Portugal, durante o período de seis meses, tendo como órgão financiador a Coordenação de Aperfeiçoamento de Pessoal de Nível Superior - CAPES/Brasil, através do Programa de Doutorado no País com Estágio no Exterior - PDEE, culminando com o presente estudo.

Em Portugal o número de casos reais de Doenças Sexualmente Transmissíveis - DSTs não é conhecido, segundo se afirma no Plano Nacional de Saúde 2004-2010 deste país ${ }^{(1)}$. Os dados disponíveis indicam que a maior incidência se verifica em homens com idades entre 25 e 44 anos. O número de doentes nas consultas de DST tem aumentado e, como no restante da Europa tem-se verificado um aumento destas infecções, acredita-se que também em Portugal, o número de novos casos tenha aumentado nos últimos anos. Adolescentes e adultos jovens são geralmente os mais afetados, apesar de se conhecer muito pouco sobre a prevalência desses agravos em grupos específicos(1).

Paralelamente, a elevada prevalência do Vírus da Imunodeficiência Humana - HIV em Portugal parece indicar que existem números elevados de outras DSTs. Sabe-se também que entre os fatores reconhecidos como responsáveis pela maior incidência das DSTs nos últimos anos, encontram-se os comportamentos sexuais de risco e a deterioração das respostas do setor saúde no controle das mesmas $^{(1)}$.

Em relação à Síndrome da Imunodeficiência Adquirida - SIDA, dados demonstram que 3/4 da mortalidade ocorreu entre 25 e 44 anos e que o número de mulheres falecidas por esta infecção tem aumentado(1). A transmissão pela partilha de material injetável para o consumo de drogas está diminuindo, enquanto a transmissão no contexto das relações heterossexuais está aumentando(2).

Diante de um panorama em que se evidenciam aumentos crescentes, ao longo dos anos, dos casos de DSTs e SIDA, torna-se relevante a proposição de estratégias preventivas que visem à minimização de comportamentos de risco a estes agravos. Programas da prevenção e de cuidado relativos à transmissão sexual do HIV e, que podem se estender as DSTs estão indicados para os países da União Européia, recomendando-se campanhas inovadoras e mais direcionadas para a promoção da saúde das comunidades $^{(3)}$.

Entende-se que, em conformidade com esta recomendação, encontram-se as ações de educação sexual voltadas aos adolescentes no contexto escolar. Dentro desta perspectiva se insere o Programa Educação da Sexualidade na Escola, planejado por uma equipe de professoras da Escola Superior de Enfermagem do Porto e desenvolvido desde 2003 em algumas escolas do Grande do Porto - Portugal.

Este programa foi planejado para ser desenvolvido em escolas da rede pública, junto aos pais, professores e alunos do 70 ao $12^{\circ}$ ano de escolaridade e na sua estrutura constam três componentes: biológico, psico-afetivo e construção de um projeto de vida, que procuram articular conhecimentos anátomo-fisiológicos ligados a reprodução, aos sentimentos e afetos das relações e a responsabilidade das pessoas com os seus envolvimentos afetivos e físicos, com vista à construção de uma vida sexual saudável(4).

Reconhecendo na estrutura desse programa um espaço potencial para pesquisar aspectos relativos a comportamentos de prevenção as DSTs e, de modo especial a SIDA, propôs-se a realização de um estudo sobre crenças relacionadas a um comportamento específico - o uso do preservativo durante as relações sexuais, tendo em vista constituir--se o meio mais eficaz que se dispõe na atualidade para prevenir estas infecções em pessoas sexualmente ativas.

Em virtude do alvo da pesquisa envolver o levantamento de crenças de uma determinada população, acerca de um comportamento específico e dentro de um contexto específico, adotou-se como base teórico-metodológica a Theory of Reasoned Action - TRA ${ }^{(5)}$, já que em sua estrutura apresentam as crenças como construtos que influenciam componentes atitudinais e normativos que, por sua vez, podem influenciar a intenção comportamental e, esta, o comportamento.

De maneira geral, a teoria baseia-se na hipótese de que os indivíduos são completamente racionais e fazem uso sistemático das informações que Ihes são disponíveis, ou seja, antes de realizarem ou não dado comportamento avaliam as consequências de suas ações. Para os autores, a maioria das ações de relevância social está sob controle volitivo, ou seja, decorrem da vontade do indivíduo em desempenhá-la e, consistente com esta suposição, a teoria visa à intenção que uma pessoa tem ou não de realizar um comportamento(5).

A Theory of Reasoned Action - TRA ${ }^{(5)}$ pode ser utilizada para predizer, explicar e influenciar o comportamento humano em contextos específicos. Para predizer um comportamento de interesse, faz-se necessário, em primeiro lugar, identificá-lo e 
mensurá-lo. Se este está claramente definido, é possível perguntar o que o determina.

O levantamento das crenças relacionadas, negativa ou positivamente, a um determinado comportamento é a etapa inicial de aplicação da teoria e serve de base para a predição e explicação do comportamento investigado.

Assim, estudos que utilizem como suporte este referencial teórico-metodológico podem evidenciar resultados que contribuam com ações que visem a promoção da saúde dos adolescentes, podendo servir de base para que, programas de educação sexual desenvolvidos no ambiente escolar, realizem avaliações e reflexões sobre a necessidade de ajustes nas estratégias implementadas, procurando atuar diretamente sobre as crenças que possam influenciar a adoção de comportamentos preventivos a SIDA, notadamente no que diz respeito ao uso do preservativo durante as relações sexuais.

Ante a essas considerações, os objetivos propostos para a pesquisa em tela foram, identificar as crenças comportamentais e normativas de adolescentes portugueses em relação ao uso do preservativo durante as relações sexuais e apresentar sugestões que possam contribuir com as estratégias desenvolvidas no Programa Educação da Sexualidade na Escola.

\section{METODOLOGIA}

Trata-se de um estudo exploratório-descritivo, de natureza predominantemente quantitativa, para o qual se utilizou como referencial teórico-metodológico a Theory of Reasoned Action - TRA(5). Esta teoria apresenta cinco construtos - as crenças comportamentais (e as avaliações de suas consequências), a atitude, as crenças normativas (e as motivações para concordar), a norma subjetiva e a intenção comportamental, para predizer e explicar comportamentos específicos, considerando ainda a importância relativa dos componentes atitudinais e normativos. Este estudo se restringiu ao levantamento das crenças comportamentais e normativas relacionadas ao uso do preservativo durante as relações sexuais. Foi realizado em duas escolas públicas, localizadas no Grande Porto Portugal, onde é desenvolvido o Programa Educação da Sexualidade na Escola.

A amostra foi constitituída por 252 adolescentes, de ambos os sexos, com idade entre 13 e 19 anos, que cursavam o 90, $10^{\circ}$ e $11^{\circ}$ ano de ensino e que haviam participado das sessões do programa. A coleta de dados foi realizada mediante aplicação de um questionário, contendo questões fechadas e abertas, no período de janeiro a março de 2008 .

Os dados sócio-demográficos foram analisados considerando as frequências absoluta e percentual e as respostas relativas às crenças comportamentais e normativas ao uso do preservativo foram analisadas a partir do conteúdo e frequência, formando categorias pela similitude das crenças e determinando as modais salientes positivas e negativas (aquelas que apresentaram no mínimo três ocorrências para o grupo masculino e para o feminino), sendo estes dados apresentados em tabelas com números absolutos e percentuais.

Em atendimento a Resolução No 196/96(6), o projeto foi encaminhado ao Comitê de Ética em Pesquisa - CEP, da Universidade Federal da Paraíba/Brasil, obtendo parecer favorável. Em Portugal, o levantamento dos dados fez parte do protocolo existente entre as escolas pesquisadas e a Escola Superior de Enfermagem do Porto, em face do Programa Educação da Sexualidade na Escola, seguindo todos os trâmites éticos recomendados.

\section{RESULTADOS E DISCUSSÃO}

Considerando os preceitos da TRA(5), para a realização deste estudo foi claramente delimitada a população alvo e o comportamento sobre o qual foram investigadas as crenças modais salientes, já que culturas diferentes, bem como distintos subgrupos de uma mesma cultura podem apresentar crenças comportamentais e referentes distintos para um determinado comportamento.

Inicialmente são apresentados os dados relativos ao perfil sócio-demográfico da amostra selecionada e a seguir as crenças comportamentais e normativas relacionadas ao uso do preservativo durante as relações sexuais.

A maioria dos participantes tinha 14 e 15 anos de idade, representando $58,7 \%$ e $20,6 \%$ da amostra, respectivamente. A média de idade apresentada foi de 14,7 anos, com o desvio padrão igual a 1,05. A participação feminina foi discretamente maior do que a masculina, conforme observado na Tabela 1 . 
Tabela 1: Distribuição dos adolescentes segundo idade e sexo. Porto - PT, 2008.

\begin{tabular}{|c|c|c|c|c|c|c|}
\hline \multirow{3}{*}{ Idade } & \multicolumn{4}{|c|}{ Sexo } & \multicolumn{2}{|c|}{ Total } \\
\hline & \multicolumn{2}{|c|}{ Masculino } & \multicolumn{2}{|c|}{ Feminino } & \multirow{2}{*}{$\mathbf{N}$} & \multirow{2}{*}{$\%$} \\
\hline & $\mathbf{N}$ & $\%$ & $\mathbf{N}$ & $\%$ & & \\
\hline 13 & 1 & 0,8 & - & - & 1 & 0,4 \\
\hline 14 & 77 & 63,6 & 71 & 54,2 & 148 & 58,7 \\
\hline 15 & 24 & 19,8 & 28 & 21,4 & 52 & 20,6 \\
\hline 16 & 12 & 9,9 & 19 & 14,5 & 31 & 12,3 \\
\hline 17 & 4 & 3,3 & 11 & 8,4 & 15 & 6,0 \\
\hline 18 & 1 & 0,8 & 2 & 1,5 & 3 & 1,2 \\
\hline 19 & 2 & 1,7 & - & - & 2 & 0,8 \\
\hline Total & 121 & 100,0 & 131 & 100,0 & 252 & 100,0 \\
\hline
\end{tabular}

Embora tenham sido abrangidos os adolescentes na faixa etária delimitada para o estudo, somente participaram da amostra aqueles que cursavam o 90 , o $10^{\circ}$ e o $11^{\circ}$ ano de escolaridade, sendo que a grande maioria estava cursando o 90 ano, correspondendo a $82,9 \%$ da amostra, conforme observado na Tabela 2.

Tabela 2: Distribuição dos adolescentes, segundo idade e escolaridade. Porto - PT, 2008.

\begin{tabular}{|c|c|c|c|c|c|c|c|c|}
\hline \multirow{3}{*}{ Idade } & \multicolumn{6}{|c|}{ Escolaridade } & \multirow{2}{*}{\multicolumn{2}{|c|}{ Total }} \\
\hline & \multicolumn{2}{|c|}{90} & & \multicolumn{2}{|c|}{$11^{\circ}$} & & \\
\hline & $\mathbf{N}$ & $\%$ & $\mathbf{N}$ & $\%$ & $\mathbf{N}$ & $\%$ & $\mathbf{N}$ & $\%$ \\
\hline 13 & 1 & 0,4 & - & - & - & - & 1 & 0,4 \\
\hline 14 & 148 & 58,7 & - & - & - & - & 148 & 58,7 \\
\hline 15 & 46 & 18,2 & 5 & 2,0 & 1 & 0,4 & 52 & 20,6 \\
\hline 16 & 11 & 4,4 & 6 & 2,4 & 14 & 5,5 & 31 & 12,3 \\
\hline 17 & 2 & 0,8 & 2 & 0,8 & 11 & 4,4 & 15 & 6,0 \\
\hline 18 & - & - & 1 & 0,4 & 2 & 0,8 & 3 & 1,2 \\
\hline 19 & 1 & 0,4 & - & - & 1 & 3,4 & 2 & 0,8 \\
\hline Total & 209 & 82,9 & 14 & 5,6 & 29 & 11,5 & 252 & 100,0 \\
\hline
\end{tabular}

Verifica-se que a maioria dos adolescentes participantes da pesquisa (com 14 e 15 anos) estava cursando o 90 ano, portanto com idade compatível para a escolaridade. Dados do Instituto Nacional de Estatística - $\operatorname{INE}^{(7)}$ apontam que em 2004, a taxa real de escolarização segundo o nível de educação e ensino (relação percentual entre o número de alunos matriculados num determinado ciclo, em idade normal de frequência do mesmo e a população residente dos mesmos níveis etários) para o 30 ciclo ( 70 ao 90 ano) foi de $82,5 \%$. Tendo em vista que poucos adolescentes pesquisados estão com idade incompatível para a escolaridade, os dados obtidos mostram-se coerentes com a realidade apontada pelo INE naquele ano.
Para efeito de análise das condições socioeconômica dos adolescentes foram inseridas no instrumento questões acerca da escolaridade e da profissão dos seus pais e mães, devido não ser uma prática dos pesquisadores portugueses a inclusão de questionamentos sobre a renda familiar nos estudos que realizam.

Quanto à escolaridade, observa-se na Tabela 3 que um pouco mais de $50 \%$ dos pais e das mães tinham formação igual ou superior ao ensino secundário, sendo que aproximadamente $25 \%$ dos pais e $30 \%$ das mães haviam concluído o ensino universitário. Cerca de $20 \%$ tinha concluído apenas o 10 e $2^{\circ}$ ciclos.

Tabela 3: Distribuição dos adolescentes, segundo a escolaridade dos pais e das mães. Porto - PT, 2008.

\begin{tabular}{|c|c|c|c|c|}
\hline \multirow{2}{*}{ Escolaridade } & \multicolumn{2}{|c|}{ Pai } & \multicolumn{2}{|c|}{ Mãe } \\
\hline & $\mathbf{N}$ & $\%$ & $\mathbf{N}$ & $\%$ \\
\hline Não respondeu & 17 & 6,7 & 11 & 4,4 \\
\hline $1^{\circ}$ ciclo & 27 & 10,7 & 31 & 12,3 \\
\hline 20 ciclo & 21 & 8,3 & 25 & 9,9 \\
\hline 30 ciclo & 58 & 23,0 & 49 & 19,4 \\
\hline Ensino Secundário & 62 & 24,6 & 56 & 22,2 \\
\hline Ensino Universitário & 62 & 24,6 & 72 & 28,6 \\
\hline Pós-licenciado & 5 & 2,0 & 8 & 3,2 \\
\hline Total & 252 & 100,0 & 252 & 100,0 \\
\hline
\end{tabular}


A classificação das profissões exercidas pelos pais e mães dos adolescentes foi realizada de acordo com a Classificação Nacional das Profissões de 1994 (CNP-94), obtida no site do Instituto Nacional de Estatística (INE) de Portugal. Para efeito de adequação aos dados obtidos, foi retirado o grande grupo 6 da CNP-94, em virtude de não haver nem uma ocorrência para 0 mesmo. Foram ainda introduzidas quatro categorias para incluir profissões ou situações que não se enquadravam na CNP-4, conforme pode ser observado na Tabela 4.

Tabela 4: Distribuição dos adolescentes, segundo a profissão dos pais e mães. Porto - PT, 2008.

\begin{tabular}{ccccc}
\hline Profissões & Pais & \multicolumn{2}{c}{ Mães } \\
Quadros Superiores da Administração Pública, Dirigentes e & N & $\mathbf{\%}$ & N & \% \\
Quadros Superiores de Empresas & 27 & 10,7 & 11 & 4,7 \\
Especialistas das Profissões Intelectuais e Científicas & 42 & 16,7 & 51 & 20,2 \\
Técnicos e Profissionais de Nível Intermédio & 26 & 10,3 & 30 & 11,9 \\
Pessoal Administrativo e Similares & 40 & 15,9 & 52 & 20,6 \\
Pessoal dos Serviços e Vendedores & 29 & 11,5 & 37 & 14,6 \\
Operários, Artífices e Trabalhadores Similares & 10 & 4,0 & 02 & 0,8 \\
Operadores de Instalações e Máquinas e Trabalhadores da & 28 & 11,1 & - & - \\
Montagem & 07 & 2,8 & 06 & 2,4 \\
Trabalhadores não Qualificados & 04 & 1,6 & - & - \\
Membros das Forças Armadas & 06 & 2,4 & 02 & 0,8 \\
Reformado (a) & 09 & 3,6 & 16 & 6,3 \\
Desempregado (a) & 02 & 0,8 & 30 & 11,9 \\
Outros* & 22 & 8,7 & 15 & 5,9 \\
Não respondeu & $\mathbf{2 5 2}$ & $\mathbf{1 0 0 , 0}$ & $\mathbf{2 5 2}$ & $\mathbf{1 0 0 , 0}$ \\
\hline Total & & &
\end{tabular}

*Incluiu: dona de casa, falecido, astróloga e topógrafo.

Em relação aos pais verifica-se que as principais profissões correspondem àquelas ligadas às áreas intelectuais e científicas $(16,7 \%)$, para as quais é necessária formação de nível superior. Em seguida estão profissões ligadas à área administrativa $(15,9 \%)$, normalmente exercidas em bancos ou outras empresas. Para as mães observa-se situação semelhante, invertendo-se apenas a ordem com que aparecem estas profissões, correspondendo a $20,6 \%$ e 20,2\%. Entretanto, verifica-se na Tabela 4, que os pais ocupam mais cargos em quadros superiores da administração pública ou de empresas $(10,7 \%)$ do que as mães $(4,7 \%)$. Por conseguinte, as mães exercem mais profissões de nível técnico $(11,9 \%)$ e de prestação de serviços $(14,6 \%)$ do que os pais (10,3\% e $11,5 \%$, respectivamente).

Tomou-se como parâmetro para análise do nível sócio-econômico do grupo pesquisado, a classificação proposta por Ribeiro ${ }^{(8)}$, na qual considera o nível de escolaridade e as profissões dos pais e mães para estabelecer os níveis sócio-econômico em elevado, médio e baixo, priorizando aqueles que tenham melhores situações. De acordo com esta classificação, as mães apresentaram melhores níveis de escolaridade e de profissões, situando $28,2 \%$ do grupo pesquisado no nível sócio-econômico elevado, $16 \%$ no médio e $7,6 \%$ no baixo. Não foi possível estabelecer a classificação para a totalidade da amostra, em virtude de, em alguns casos, não haver compatibilidade dos dados com a classificação adotada $e$, em outros, por não terem sido respondidas as questões acerca da escolaridade e/ou profissão dos genitores.

o nível sócio-econômico é um aspecto importante a ser considerado em pesquisas, cujo alvo seja aspectos ligados à saúde, tendo em vista que, normalmente as pessoas com melhor status sócioeconômico têm maior acesso aos meios de comunicação, informação, formação e aos serviços de saúde, fator que pode concorrer para busca e manutenção de melhores condições de saúde. As condições sócio-econômicas, bem como fatores de ordem psicológica e estilos de vida, estão independentemente relacionados com a saúde, podendo exercer efeito positivo ou negativo sobre esta. Portanto, mostra-se pertinente a atenção a estes aspectos, a fim de adequar ações em saúde às características da população ao qual se destinam(9).

Os dados concernentes à iniciação sexual evidenciam que um pequeno número de adolescentes, aproximadamente $15 \%$, respondeu positivamente a esta questão, sendo que as idades atuais destes situaram-se, especialmente, entre $14 \mathrm{e}$ 16 anos. Entre os adolescentes que iniciaram a atividade sexual, $54 \%$ são do sexo masculino, evidenciando um equilíbrio dos dados desta variável com relação ao gênero (Tabela 5). 
Tabela 5: Distribuição dos adolescentes, segundo a idade de iniciação sexual.Porto - PT, 2008.

\begin{tabular}{|c|c|c|c|c|c|c|c|c|}
\hline \multirow{3}{*}{ Idade } & \multicolumn{6}{|c|}{ Iniciação Sexual } & \multirow{2}{*}{\multicolumn{2}{|c|}{ Total }} \\
\hline & \multicolumn{2}{|c|}{ Não responde } & \multicolumn{2}{|c|}{ Sim } & \multicolumn{2}{|c|}{ Não } & & \\
\hline & $\mathbf{N}$ & $\%$ & $\mathbf{N}$ & $\%$ & $\mathbf{n}$ & $\%$ & $\mathbf{N}$ & $\%$ \\
\hline 13 & - & - & - & - & 1 & 0,4 & 1 & 0,4 \\
\hline 14 & 2 & 0,8 & 9 & 3,6 & 137 & 54,3 & 148 & 58,7 \\
\hline 15 & - & - & 9 & 3,6 & 43 & 17,0 & 52 & 20,6 \\
\hline 16 & - & - & 10 & 4,0 & 21 & 8,3 & 31 & 12,3 \\
\hline 17 & - & - & 7 & 2,8 & 8 & 3,2 & 15 & 6,0 \\
\hline 18 & - & - & 2 & 0,8 & 1 & 0,4 & 3 & 1,2 \\
\hline 19 & - & - & - & - & 2 & 0,8 & 2 & 0,8 \\
\hline Total & 2 & 0,8 & 37 & 14,7 & 213 & 84,5 & 252 & 100,0 \\
\hline
\end{tabular}

Embora não tenham sido questionados acerca da idade de início da vida sexual, acredita-se que, possivelmente, a primeira relação desses jovens não tenha ocorrido muito antes das suas idades atuais, já que pesquisas desenvolvidas com adolescentes portugueses identificaram idades semelhantes à encontradas nesta investigação. Como exemplo pode-se citar pesquisa efetivada junto a 209 adolescentes grávidas, em que (67,9\%) iniciou a vida sexual com idades entre $15-17$ anos e $(16,7 \%)$ com 14 anos ou menos ${ }^{(10)}$. Logo, a inferência acima aludida se coaduna com os resultados de estudos realizados entre adolescentes portugueses.

Em relação à análise das crenças, verifica-se na Tabela 6 que foram apresentadas 411 crenças concernentes às vantagens (crenças positivas) de usar o preservativo durante as relações sexuais. Destas, 97,8\% foram modais salientes e, após a categorização, as principais crenças ficaram assim distribuídas, prevenção de DST's (52,1\%), da gravidez $(41,8 \%)$ e da SIDA (3,9\%). Importante salientar que antes da categorização observou-se que muitos dos respondentes emitiram até três vantagens para o uso do preservativo. Evidencia-se ainda que os sujeitos do sexo feminino apresentaram um percentual ligeiramente maior de crenças comportamentais positivas ao uso do preservativo em relação ao masculino.

Tabela 6: Distribuição das crenças comportamentais positivas modais salientes, em relação ao uso do preservativo. Porto - PT, $2008(\mathrm{~N}=411)$.

\begin{tabular}{|c|c|c|c|c|c|c|}
\hline \multirow{3}{*}{$\begin{array}{c}\text { Crenças comportamentais positivas } \\
\text { (vantagens) }\end{array}$} & \multicolumn{4}{|c|}{ Sexo } & \multirow{2}{*}{\multicolumn{2}{|c|}{ Total }} \\
\hline & \multicolumn{2}{|c|}{ Masculino } & \multicolumn{2}{|c|}{ Feminino } & & \\
\hline & $\mathbf{N}$ & $\%$ & $\mathbf{N}$ & $\%$ & $\mathbf{N}$ & $\%$ \\
\hline Prevenção DST & 101 & 24,6 & 113 & 27,5 & 214 & 52,1 \\
\hline Prevenção Gravidez & 77 & 18,7 & 95 & 23,1 & 172 & 41,8 \\
\hline Prevenção SIDA & 08 & 1,9 & 08 & 1,9 & 16 & 3,9 \\
\hline Idiossincráticas & 03 & 0,7 & 06 & 1,5 & 09 & 2,2 \\
\hline Total CCMS* & 186 & 45,2 & 216 & 52,5 & 402 & 97,7 \\
\hline Total & 189 & 45,9 & 222 & 54,0 & 411 & 100,0 \\
\hline
\end{tabular}

*Crenças Comportamentais Modais Salientes.

Os resultados obtidos apresentam semelhança com estudos realizados no Brasil, nos quais as mesmas crenças foram emitidas por adolescentes de ambos os sexos e com a mesma faixa etária(11). Por sua vez, estudo realizado para conhecer os discursos de adolescentes sobre práticas sexuais seguras ou não, evidenciou que o uso do preservativo foi um dos métodos contraceptivos enfatizados por eles, como necessário para o exercício da atividade sexual com menor risco de gravidez e de infecção por DSTs(12).

De acordo com a TRA, as crenças modais salientes são determinantes imediatos da atitude da pessoa em relação a um comportamento e, dependendo do tempo e do incentivo, uma pessoa pode considerar um número maior de crenças. Porém, um número pequeno de crenças está sujeito a mudanças, podendo ser fortalecidas, debilitadas ou ainda substituídas por crenças novas ${ }^{(5)}$.

Considerando este pressuposto, pode-se inferir que, se as crenças positivas modais salientes identificadas no grupo estudado forem abordadas e reforçadas sistematicamente durante as sessões do Programa Educação da Sexualidade na Escola, podem resultar em grande contribuição no que concerne a prevenção, não somente do HIV/SIDA, como também das DSTs e da gravidez indesejada, aproveitando as oportunidades que se assentam no próprio ambiente escolar, espaço privilegiado para lidar com questões relativas à saúde dos adolescentes. Acerca da relevância de ações de promoção da saúde no contexto escolar, pesquisadores ressaltam o seu valor no sentido de garantir o desenvolvimento 
saudável dos jovens, a partir de um processo de capacitação para agir e intervir no decurso da sua vida(13).

Em relação às crenças comportamentais negativas ao uso do preservativo, foram emitidas 240. As crenças modais salientes totalizaram $97,1 \%$ e após a análise constituíram oito categorias, sendo as principais: risco de romper $(24,6 \%)$, diminuição do prazer (24,6\%) e incômodo/desconforto (22,5\%). Vale ressaltar que, antes da categorização verificouse que foram referidas por muitos participantes do estudo mais de uma desvantagem para o uso do preservativo, chegando inclusive alguns a mencionarem até quatro desvantagens. Outro aspecto interessante observado refere-se à variedade de desvantagens apontada pelo grupo pesquisado, sendo seis as constituídas para o sexo masculino e oito para o sexo feminino. Evidencia-se ainda que as mulheres acreditam muito mais no risco de romper o preservativo durante o ato sexual do que os homens. Esta relação se inverte quando a crença diz respeito à diminuição do prazer e ao incômodo/desconforto (Tabela 7).

Tabela 7: Distribuição das crenças comportamentais negativas modais salientes, em relação ao uso do preservativo. Porto - PT, 2008.

\begin{tabular}{|c|c|c|c|c|c|c|}
\hline \multirow{3}{*}{$\begin{array}{c}\text { Crenças comportamentais negativas } \\
\text { (desvantagens) }\end{array}$} & \multicolumn{4}{|c|}{ Sexo } & \multirow{2}{*}{\multicolumn{2}{|c|}{ Total }} \\
\hline & \multicolumn{2}{|c|}{ Masculino } & \multicolumn{2}{|c|}{ Feminino } & & \\
\hline & $\mathbf{N}$ & $\%$ & $\mathbf{N}$ & $\%$ & $\mathbf{N}$ & $\%$ \\
\hline Risco de romper & 20 & 8,3 & 39 & 16,3 & 59 & 24,6 \\
\hline Diminuição do Prazer & 31 & 12,9 & 28 & 11,7 & 59 & 24,6 \\
\hline Incômodo & 30 & 12,5 & 24 & 10,0 & 54 & 22,5 \\
\hline Alergia & 06 & 2,5 & 11 & 4,6 & 17 & 7,1 \\
\hline Risco de Gravidez & 07 & 2,9 & 09 & 3,8 & 16 & 6,7 \\
\hline Risco de DST & 07 & 2,9 & 07 & 2,9 & 14 & 5,8 \\
\hline Não é $100 \%$ eficaz & - & - & 07 & 2,9 & 7 & 2,9 \\
\hline Risco de ficar preso & - & - & 06 & 2,5 & 6 & 2,5 \\
\hline Idiossincráticas & 07 & 2,9 & 01 & 0,4 & 8 & 3,3 \\
\hline Total de CCMS* & 101 & 42,0 & 131 & 54,7 & 232 & 96,7 \\
\hline Total & 108 & 45,0 & 132 & 55,0 & 240 & 100,0 \\
\hline
\end{tabular}

*Crenças Comportamentais Modais Salientes.

A evidência da variedade de categorias identificadas para as crenças comportamentais negativas merece ser ressaltada, tendo em vista que os adolescentes portugueses do sexo masculino emitiram um número bem mais expressivo de crenças negativas ao comportamento estudado quando comparados com adolescentes participantes de estudos semelhantes realizados no Brasil, nos quais foram apenas três as categorias identificadas. Para as adolescentes, a situação encontrada deve dispensar ainda mais atenção, já que foram identificadas oito categorias de crenças negativas contra apenas duas (diminuição da sensibilidade e discriminação) identificadas nos estudos mencionados(11).

O risco de o preservativo romper se constituiu em uma das principais crenças negativas citadas pelo grupo, tendo também sido mencionado, em menor freqüência e somente pelas adolescentes, o risco de ficar preso na vagina ou no reto. Falhas nos preservativos estão relacionadas a rompimentos ou a saída dos mesmos durante o ato sexual, entretanto constituem-se situações incomuns, segundo informações da World Health Organization - WHO(14).

Acerca destes aspectos é importante ressaltar que o rompimento e a saída do preservativo durante o intercurso sexual podem estar relacionados à (o): colocação inadequada do mesmo (pela presença de ar no reservatório situado na ponta do preservativo; não colocação do preservativo até a base do pênis); escolha de um preservativo incompatível com o tamanho do pênis (pequeno ou grande para o órgão); baixa qualidade do produto; vencimento do prazo de validade; armazenamento inadequado, entre outros(15). Portanto, para minimizar crenças dessa natureza são necessárias atividades educativas não só teóricas, mas também práticas em modelos da genitália externa masculina, com demonstração da colocação correta do preservativo, proporcionar os devidos esclarecimentos sobre 0 uso e o seu armazenamento adequado.

Semelhante aos dados encontrados nesta pesquisa, as categorias incômodo e diminuição da sensibilidade (prazer), emitidas pelos adolescentes do sexo masculino também foram identificadas nos estudos realizados no Brasil(11). A maioria das pessoas sexualmente ativas não faz uso do preservativo por razões ligadas, entre outros aspectos, a diminuição do prazer pessoal e do parceiro e pelo fato de o considerarem inconveniente e incômodo(16).

Torna-se relevante considerar que, do total de adolescentes pesquisados, $14,7 \%$ tem vida sexual ativa. Diante disso, é preocupante que um índice tão 
expressivo de adolescentes manifeste crenças negativas dessa natureza, antes mesmo de iniciarem sua vida sexual, o que pode concorrer para sua manutenção após a iniciação sexual e ocasionar práticas desprotegidas, em nome de um "possível" aumento da sensibilidade e, consequentemente, do prazer.

As categorias de riscos de gravidez e de DSTs também foram emitidas pelo grupo estudado. Pesquisas revelam que o preservativo constitui-se no único método contraceptivo comprovado para reduzir o risco das doenças sexualmente transmissíveis (DST), incluindo o HIV e pode ser usado como um método de dupla finalidade, tanto para a prevenção da gravidez como das DSTs ${ }^{(14)}$.

Especificamente ao risco de gravidez, mostra-se pertinente esclarecer que as estimativas das taxas para sua ocorrência pela WHO ${ }^{(14)}$, considerando o uso consistente e correto do preservativo em todos os intercursos sexuais é de $3 \%$ em doze meses. Este índice pode aumentar para $10 \%$ a $14 \%$ nos casos de uso inadequado e não por falha do preservativo.

A eficácia do preservativo para prevenção da infecção pelo HIV e DSTs não é total, entretanto estudos prospectivos em casais sorodiscordantes evidenciaram que com o uso do preservativo, a taxa de infecção pelo vírus entre parceiros não infectados foi menor que $1 \%$ ao ano(14). Já as informações do Programa Nacional de DST/AIDS (17), revelam que o uso correto e sistemático do preservativo em todas as relações sexuais apresenta uma efetividade estimada de $95 \%$ na prevenção da transmissão das DST e SIDA. Dados dessa natureza evidenciam um índice de proteção bastante significativo, o que faz tornar de extrema pertinência e relevância a abordagem e o estímulo ao uso do preservativo nas ações educativas que visem o desenvolvimento sexual saudável dos jovens.

No que concerne às crenças ligadas às alergias ao látex, estas são muito raras entre a população em geral. O Center for Disease Control, estima que a população em risco de apresentar reação alérgica ao látex é de $0,08 \%$, bem como a natureza da reação tende a ser muito ligeira. Preocupações com alergias ao látex não devem inibir pessoas sexualmente ativas de usarem o preservativo, uma vez que os riscos associados com o contacto sexual desprotegido são muito superiores aos da exposição com o uso do mesmo ${ }^{(14)}$.

Os resultados negativos em relação ao uso do preservativo são de extrema importância, tendo em vista que o peso de uma crença negativa em relação a um determinado comportamento constitui-se barreira importante para a sua realização. Por conseguinte, necessário se faz frisar aos adolescentes as diversas vantagens do uso correto e sistemático do preservativo, tais como: baixo custo e fácil disponibilidade; desfrutar de práticas sexuais mais seguras; retardar o orgasmo masculino, tornando a relação mais prazerosa e ter relações sem se preocupar com gravidez indesejada ou DSTs e SIDA(15). Assim, pode-se ao longo do tempo substituir as crenças negativas por crenças positivas, favorecendo e mantendo a saúde sexual dos adolescentes.

Quanto às crenças normativas, evidenciaram-se sete categorias de referentes positivos para o grupo estudado, dos quais se destacam: amigos (30,2\%), pais $(27,8 \%)$ e família $(20,7)$. Se adicionarmos à categoria família todos os referentes que a ela se relacionam (pai, irmão, mãe) obtém-se um total de, aproximadamente $60 \%$, percentual que coloca os familiares como elementos principais na relação como os adolescentes, quando o assunto diz respeito ao uso do preservativo durante as relações sexuais (Tabela 8). 
Tabela 8: Distribuição das crenças normativas positivas modais salientes em relação ao uso do preservativo. Porto - PT, 2008.

\begin{tabular}{ccccccc}
\hline \multirow{2}{*}{ Referentes positivos } & \multicolumn{2}{c}{ Masculino } & \multicolumn{2}{c}{ Feminino } & \multicolumn{2}{c}{ Total } \\
& $\mathbf{N}$ & $\mathbf{\%}$ & $\mathbf{N}$ & $\mathbf{\%}$ & $\mathbf{N}$ & \% \\
\hline Amigos (as) & 36 & 12,2 & 53 & 18,0 & 89 & 30,2 \\
Pai & 34 & 11,5 & 48 & 16,3 & 82 & 27,8 \\
Família & 35 & 11,9 & 26 & 8,8 & 61 & 20,7 \\
Irmã(o) & 05 & 1,7 & 20 & 6,8 & 25 & 8,5 \\
Namorado(a) & 10 & 3,4 & 10 & 3,4 & 20 & 6,8 \\
Mãe & - & - & 08 & 2,7 & 8 & 2,7 \\
Professores & 03 & 1,0 & - & - & 3 & 1,0 \\
Idiossincráticas & 01 & 0,3 & 06 & 2,0 & 7 & 2,4 \\
\hline Total CNMS* & $\mathbf{1 2 3}$ & $\mathbf{4 1 , 7}$ & $\mathbf{1 6 5}$ & $\mathbf{5 6 , 0}$ & $\mathbf{2 8 8}$ & $\mathbf{9 7 , 7}$ \\
Total & $\mathbf{1 2 4}$ & $\mathbf{4 2 , 0}$ & $\mathbf{1 7 1}$ & $\mathbf{5 8 , 0}$ & $\mathbf{2 9 5}$ & $\mathbf{1 0 0 , 0}$ \\
\hline
\end{tabular}

*Crenças Normativas Modais Salientes.

Antes da categorização das crenças normativas foi evidenciado que a maioria dos respondentes citou mais de um referente positivo e alguns citaram até cinco. Verificou-se ainda que os referentes positivos foram citados sobretudo pelas mulheres. Apenas a categoria família foi mencionada, predominantemente, pelos homens e a categoria professores, somente por eles (Tabela 8).

Entre os adolescentes do sexo masculino, incluindo os percentuais de pais e irmãos na categoria família, obtém-se um índice de aproximadamente $25 \%$. Ao adotar o mesmo procedimento para as adolescentes, incluindo ainda as mães, o percentual atinge $35 \%$ (Tabela 8 ).

De acordo com os resultados da Tabela 8, verifica-se que os componentes do núcleo familiar correspondem aos principais referentes positivos para o grupo estudado, resultado que se coaduna com àqueles obtidos nos estudos realizados no Brasil(12). Portanto, os membros da família podem se constituir em importante via de acesso no sentido de influenciar os adolescentes a desempenharem um comportamento sexual seguro, ou o mais seguro possível.

Evidências empíricas indicam que estratégias familiares podem ter um impacto substancial sobre a saúde sexual dos seus adolescentes. Tais estratégias incluem: acompanhamento, frequentes comunicações sobre sexo e fornecimento de apoio familiar para proteção dos adolescentes envolvidos em comportamentos sexuais de risco. Tendo a família como base para intervenções pode-se ampliar o êxito na adoção das estratégias de proteção ${ }^{(18)}$. $O$ processo de educação sexual dos jovens constitui-se em grande desafio, o que implica em privilegiar a participação da família, da escola, dos profissionais de saúde e da sociedade, requerendo preparo para lidar com esta temática(12).

Ante ao exposto e enfatizando o espaço ocupado pelos referentes mais significativos identificados neste estudo, os profissionais que lidam com temas relativos à saúde sexual podem esclarecer os familiares acerca do importante papel para seus filhos adolescentes, informando-os, esclarecendo dúvidas e motivando-os a acompanhá-los mais de perto, no intuito de favorecer a promoção da saúde sexual dos mesmos.

No que se refere às crenças normativas negativas (referentes negativos), foram emitidas 19 , das quais $57,9 \%$ foram modais salientes, sendo estas, amigos (42,1\%) e avós (15,8\%). Em relação à distribuição por sexo, observa-se que a categoria amigos foi considerada modal saliente para as adolescentes (Tabela 9). 
Tabela 9: Distribuição das crenças normativas negativas modais salientes em relação ao uso do preservativo. Porto - PT, 2008.

\begin{tabular}{ccccccc}
\hline \multirow{2}{*}{ Referentes negativos } & \multicolumn{2}{c}{ Masculino } & \multicolumn{2}{c}{ Feminino } & \multicolumn{2}{c}{ Total } \\
& $\mathbf{N}$ & $\mathbf{\%}$ & $\mathbf{N}$ & $\mathbf{\%}$ & $\mathbf{N}$ & $\mathbf{\%}$ \\
\hline Amigos & 04 & 21,1 & 04 & 21,1 & 08 & 42,1 \\
Avós & 03 & 15,8 & - & - & 03 & 15,8 \\
Idiossincráticas & 03 & 15,8 & 05 & 26,3 & 08 & 42,1 \\
\hline Total CNMS* & $\mathbf{0 7}$ & $\mathbf{3 6 , 8}$ & $\mathbf{0 4}$ & $\mathbf{2 1 , 1}$ & $\mathbf{1 1}$ & $\mathbf{5 7 , 9}$ \\
Total & $\mathbf{1 0}$ & $\mathbf{5 2 , 7}$ & $\mathbf{0 9}$ & $\mathbf{4 7 , 3}$ & $\mathbf{1 9}$ & $\mathbf{1 0 0 , 0}$ \\
\hline
\end{tabular}

*Crenças Normativas Modais Salientes.

Pode-se analisar este resultado como positivo, pois no que concerne ao preservativo, o grupo estudado convive majoritariamente com pessoas significativas, que recomendam o seu uso durante as relações sexuais. Assim, considerando o baixo número de referentes negativos citados, julga-se pertinente que as ações educativas direcionadas aos adolescentes das instituições pesquisadas envolvam os referentes positivos, a fim de atuarem efetivamente como parceiros da equipe de profissionais e professores envolvidos no Programa Educação da Sexualidade na Escola.

Ante os resultados obtidos nesta investigação, considera-se que o planejamento de intervenções de cunho preventivo voltadas para os jovens constitui-se uma prioridade, sendo necessária a compreensão do contexto onde estes se inserem ${ }^{(19)}$. Entende-se que, para além do contexto, a identificação prévia das crenças construídas ao longo das vivências dos jovens, em cenários marcados por distintas características sócio-econômicas, políticas, culturais, ambientais e comportamentais é de substancial importância, a fim de que as intervenções/estratégias possam se coadunar às construções individuais e coletivas dos sujeitos aos quais se destinam, podendo assim resultar em efeitos mais promissores para a promoção da saúde dos adolescentes e jovens, notadamente no que se refere a enfermidades para as quais a ciência ainda não descobriu a cura, como a SIDA.

Some-se $a$ isso o entendimento de que a promoção da saúde não se constitui em uma responsabilidade exclusiva do setor saúde, pois transcende um estilo de vida saudável na direção de um bem-estar global(20) e deve ser entendida como compromisso individual, coletivo e institucional, gerida por todos estes atores a partir de um envolvimento responsável.

\section{CONCLUSÃO}

A partir do levantamento de crenças, tal como proposto pela TRA, é possível constatar que diferentes grupos valorizam, de forma distinta, o que denominamos aqui de crenças comportamentais e normativas. Portanto, ações educativas voltadas para comportamentos preventivos específicos, como o uso do preservativo durante as relações sexuais, devem estar direcionadas aos grupos considerando suas crenças a esse respeito. No que tange as crenças normativas, devem também dirigir-se aos referentes significativos para os sujeitos pesquisados, a fim de que possam tomar consciência e se investir no papel de motivadores da adoção de comportamentos sexuais saudáveis.

Os resultados obtidos neste estudo podem ser de grande contribuição para a equipe do Programa Educação da Sexualidade na Escola, pois crenças positivas para 0 uso do preservativo foram identificadas, podendo ser reforçadas e favorecer, ao longo do tempo, a adoção do seu uso correta e sistematicamente pelos jovens que participam das sessões do programa. Por outro lado, as crenças negativas, que muitas vezes tem por base conhecimentos errôneos ou insuficientes, podem ser alvo de debates, discussões em grupo, oficinas e/ou outras estratégias, que envolvam os referentes positivos significativos, de modo a clarificar dúvidas e a contribuir para a diminuição do número de crenças negativas ou para sua transformação em positivas.

Sabe-se que o uso do preservativo durante as relações sexuais é apenas um dos vários aspectos que perpassam a temática da saúde sexual. Entretanto, este comportamento, quando não adotado correta e sistematicamente, pode trazer sérias repercussões para a saúde nos seus aspectos físico, psíquico e social. Portanto, não se deve desperdiçar oportunidades e espaços (escola, ambiente familiar) que favoreçam a construção de comportamentos que, efetivamente, concorram para a preservação da saúde sexual dos jovens.

\section{REFERÊNCIAS}

1. Direcção Geral da Saúde, Ministério da Saúde. Plano nacional de saúde 2004-2010: mais saúde para todos. Lisboa (Portugal): Ministério da Saúde; 2004.

2. Coordenação Nacional para a Infeccção VIH/SIDA, Ministério da Saúde. Programa nacional de prevenção e controlo da infecção VIH/SIDA 2007-2010. Lisboa (Portugal): Ministério da Saúde; 2007.

3. Nardone A. Transmission of HIV/AIDS in Europe continuing. Euro Surveill. 2005;10(47):2837. 
4. Ribeiro TT. Educação da sexualidade na escola: um treino de competências. Porto: Casa do Professor; 2006.

5. Ajzen I, Fishbein M. Understanding attitudes and predicting social behavior. Englewood Clifs: Prentice Hall; 1980.

6. Ministério da Saúde; Conselho Nacional de Saúde. Resolução No 196/96 - Normas regulamentadoras de pesquisa envolvendo seres humanos. Brasília (Brasil): Ministério da Saúde; 1996.

7. Instituto Nacional de Estatística. Indicadores sociais 2006. Lisboa (Portugal): Instituto Nacional de Estatística; 2007.

8. Ribeiro TCTMT. Consumos de tabaco, álcool, haxixe e outras substâncias em meio escolar [dissertation]. Porto: Faculdade de Medicina/Universidade do Porto; 1999. 142 p.

9. Molarius A, Berglund K, Eriksson C, Lambe M, Nordstro $E$, Eriksson $H G$ et al. Socioeconomic conditions, lifestyle factors, and self-rated health among men and women in Sweden. European Journal of Public Health. 2006;17(2):125-33.

10. Abreu MSN. Identidades das grávidas adolescentes: integração do sistema familiar e das perspectivas individuais de desenvolvimento [thesis]. Porto: Instituto de Ciências Biomédicas de Abel Salazar; 2005, 135p.

11. Oliveira SHS, Dias MR, Silva MIT. Adolescentes e aids: crenças relacionadas ao uso do preservativo. Rev. Bras. Cienc. Saude. 2004;8(1):69-80.

12. Carmo R, Van der Sand ICP. O discurso dos adolescentes sobre vida sexual na adolescência. Rev. Eletr. Enf. [Internet]. 2007 [cited 2009 dez 30];9(2):417-31. Available from: http://www.fen.ufg.br/revista/v9/n2/v9n2a10.htm.

13. Monteiro MJ, Vasconcelos-Raposo J. Contextualizar os conhecimentos, atitudes e crenças face ao VIH/SIDA: um contributo para aperfeiçoar o caminho a percorrer. Psicologia, Saúde \& Doenças 2006 [cited $2009 \mathrm{dez} 30$ ];7(1):125-136. Available from:

http://www.eurosurveillance.org/ew/2005/051124.asp\#1

14. World Health Organization. Effectiveness of male latex condoms in protecting against pregnancy and sexually transmitted infections. Fact sheet [Internet]. 2000 [cited $2009 \mathrm{dez} 30$ ];(243). Available from: http://www.who.int/mediacentre/factsheets/fs243/en 15. Fundo das Nações Unidas para a Infância (UNICEF). Programa nacional de luta contra a SIDA. Questionário sobre preservativos. Angola: UNICEF; 2003.

16. Maliki AE, Omohan M E, Uwe EA. HIV/AIDS and use of condom: the role of counselors. Stud. Tribes Tribals. 2006;4(2):151-5.

17. Missão do Departamento de DST, Aids e Hepatites Virais [Internet]. Brasília: Ministério da Saúde (BR) [cited 2009 dez 30]. Política do Departamento de DST, Aids e Hepatites Virais.
Missão do Departamento. Available from: http://www.aids.gov.br/data/Pages/LUMISB9C1F777 PTBRIE.htm.

18. DiClemente RJ, Crosby RA, Salazar LF. Family influences on adolescent's sexual health: synthesis of the research and implications for clinical practice. Bentham Science Publishers. 2006;2(4):369-73.

19. Marques ES, Mendes DA, Tornis NHM, Lopes CLR, Barbosa MA. O conhecimento dos escolares adolescentes sobre Doenças Sexualmente Transmissíveis/AIDS. Rev. Eletr. Enf. [Internet]. 2006 [cited 2009 dez 30];8(1):58-62. Available from:

http://www.fen.ufg.br/revista/revista8 1/original 07.htm. 20. Monteiro AI, Medeiros JD, Oliveira JR. Estilo de vida e vulnerabilidade social dos adolescentes no Bairro de Felipe Camarão, Natal/RN, 2005. Rev. Eletr. Enf. [Internet] 2007 [cited 2009 dez 30];9(1):17690. Available from: http://www.fen.ufg.br/revista/v9/n1/v9n1a14.htm

Artigo recebido em 27.09.08.

Aprovado para publicação em 20.08.09.

Artigo publicado em 31.12.09. 